\title{
Design of Automatic Strapping Machine of Express Box for Taobao Sellers
}

\author{
Jie Xie, Mingxin Yuan", Kejun Xu, Pengfei He, Yi Shen, Qi Wang \\ (Suzhou Institute of Technology, Jiangsu University of Science and Technology, Zhangjiagang, China)
}

\begin{abstract}
In order to improve the strapping efficiency of express box for Taobao sellers, a new automatic strapping machine of express box is designed in this paper. First, the mechanical structure of the strapping machine is designed and produced according to the strapping demand; then, the electrical structure of the strapping machine is designed and the machine is controlled based on the programmable logic controller (PLC) using the Ladder. Finally, an experiment is carried out. The experimental test results show that the designed machine includes features such as transmission, strapping and tightening for express box, and meets the needs of Taobao sellers.
\end{abstract}

Keywords: Taobao seller; Express box; Strapping machine; Programmable logic controller

\section{Introduction}

Strapping machine is one of the packaging equipments and it is a tool which can strap goods with wrapping ropes or bands. Aiming at the hot-rolled large bar with diameter over $60 \mathrm{~mm}$, a new type of wire binding machine about large bar was manufactured to alleviate labor intensity of the workers in the harsh environment[1]. The wire binding machine has the characters of little area occupied, lower cost, simpleness and compaction. In order to catch the domestic enterprise needs of improving the efficiency for packaging the vermicelli, Wei et al. [2][3] successfully developed a vermicelli strapping machine with high speed, high stability, high efficient. In order to reduce the personal consumption and improve the work efficiency during the enlacing homework of fruit trees seedling, Cui et al. [4] designed a strapping machine for fruit tree seedlings. In order to improve the efficiency and reduce the great labor intensity of harvesting sugarcane, Wang et al. [5] design a sugarcane automatic binding machine which is composed by storehouse, quantitative mechanism, squeeze mechanism and knotting mechanism.

In recent years, the rapid development of the electronic business in China not only drives the consumption, but also promotes the booming development of the express delivery industry. The strapping speed directly affects the economic benefits of Taobao sellers. At present, the artificial strapping has been the role of express boxe strapping. However, when the express boxes are much more and the goods are very heavy during the actual packaging process, the efficiency of the artificial strapping is very low. In order to realize the quick strapping of express boxes, a new automatic strapping machine is designed in this paper.

\subsection{Overall design}

\section{Mechanical Design Of Strapping Machine}

According to the functional requirements of the strapping machine of express box, a machine is designed as shown in Fig. 1.

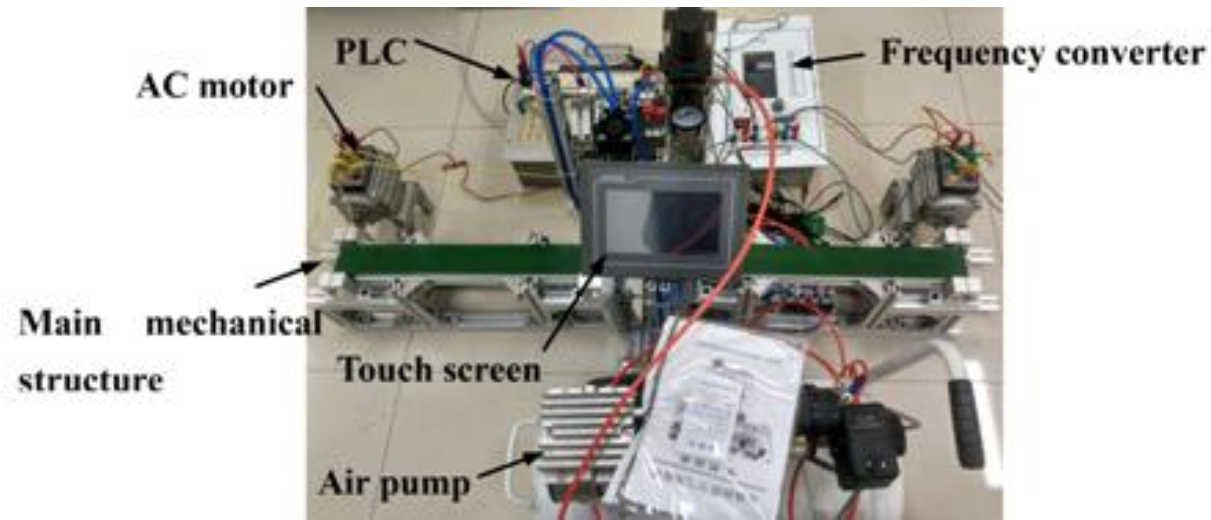

Fig. 1 Overall design of the strapping machine

* Correspondence author, mxyuan78@ hotmail.com . 
From Fig.1, we can see that besides the main mechanical structure, there are some electrical equipments, such as PLC, frequency converter, AC motor, touch screen, air pump. The mechanical structure consists of board pushing equipment, connecting equipment of strapping tape, delivery and tightening equipment of strapping tape and cutting equipment. In order to have a clear understanding of the whole strapping machine, each of the mechanical equipment is described as follows.

\subsection{Design of some key equipments}

\section{(1) Board pushing equipment}

As shown in Fig. 2, the board pushing equipment is used to prevent the strapping tape from falling out of the box-type structure. When an express box comes, the Y output port of PLC will send a signal to an electromagnetic valve, and the vale will control the two air cylinders to withdraw the piston rod. Then the strapping tape can be tightened to strap the express box. After the box is strapped, the PLC will send a signal to the electromagnetic valve to control the air cylinder, and the piston rod will be pushed. Then an enclosed conveying space for the strapping tape is formed.

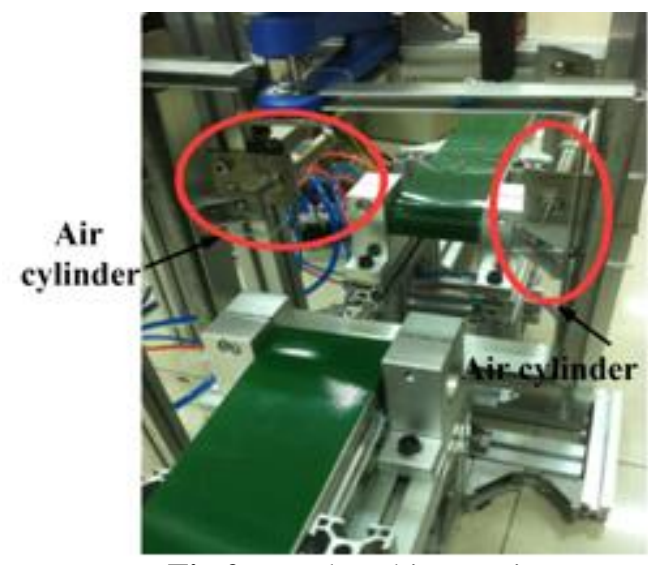

Fig.2 Board pushing equipment

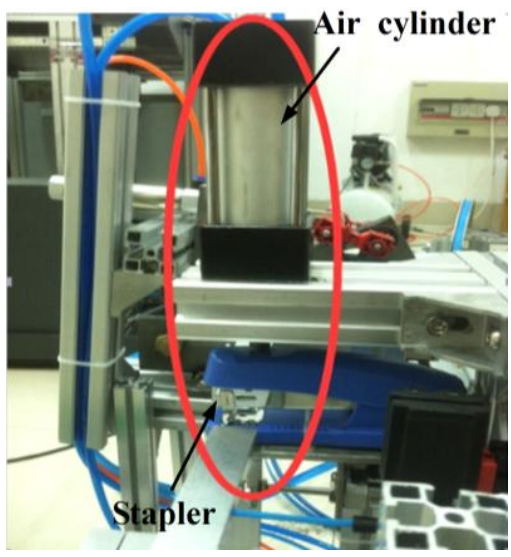

Fig.3 Connecting equipment of strapping tape

\section{(2) Connecting equipment of strapping tape}

The connecting equipment is mainly used to ensure the connecting of the head and the tail of tightening tape. As shown in Fig.3, the connection is realized through a stapler in this design. When the strapping tape is tightened, the PLC will control the air cylinder to push the piston rod trough an electromagnetic valve. Then the stapler will realize the connection of the head and the tail of tightening tape.

\section{(3) Delivery and tightening equipment}

In order to realize the transmission and the tightening of the strapping tape, a delivery and tightening equipment is designed as shown in Fig.4. From the figure, it can be seen that the equipment consists of grinding wheel and DC motor. When the strapping tape is needed to transmit, the DC motor will rotate counterclockwise to drive the grinding wheel and the strapping tape is transmitted. When the express box arrives at the designated location, the DC motor will rotate clockwise and the strapping tape is tightened with the grinding wheel.

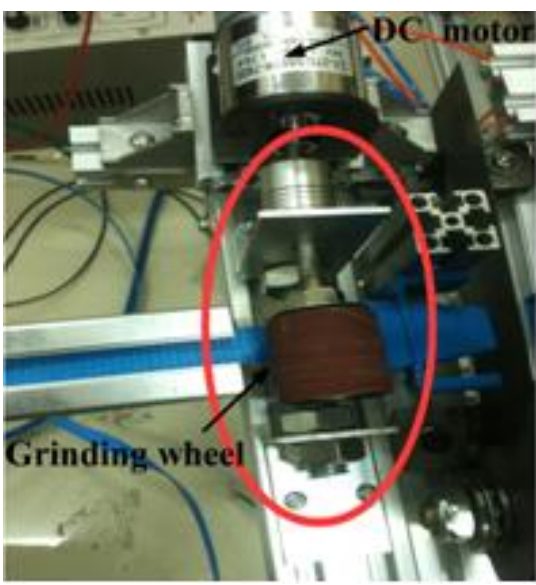

Fig.4 Delivery and tightening Equipment

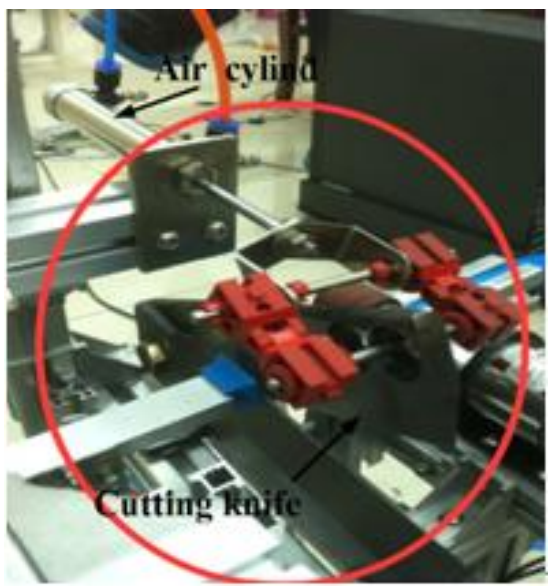

Fig.5 Cutting equipment 


\section{(4) Cutting equipment}

After the strapping tape is tightened, the tape needs to be cut. So a cutting equipment is designed as shown in Fig. 5. From the figure, we can see that the equipment consists of cutting knife and air cylinder. The pushing and withdrawing of piston rod of the air cylinder can realize the falling and uplift of the cutting knife. Then the strapping tape can be cut in time after the express box is strapped.

\subsection{Selection of main electronic components}

\section{Design Of Control System For Automatic Strapping Machine}

(1) Programmable logic controller

The PLC is the control core in our equipment. In order to complete the control task, the $\mathrm{FX}_{2 \mathrm{~N}}$ PLC is adopted.

\section{(2) $\mathrm{AC}$ motor}

In order to realize the transmission of the express box, in this design, the transmission tape is driven by two AC motors and the three phase squirrel cage induction motor whose model is WDJ24 is used in our equipment.

\section{(3) Frequency converter}

In order to regulate the speed of the AC motors, the frequency converter is used and its model is Mitsubishi D720. The power range of the converter is $0.4 \sim 7.5 \mathrm{KW}$.

(4) Pneumatic components

1) Air cylinder

In our designed strapping machine, there are three air cylinders. The three cylinder stroke is $25 \mathrm{~cm}, 30 \mathrm{~cm}, 5 \mathrm{~cm}$ respectively. In our equipment, the models of the corresponding cylinders are SC32X25, CDJ2B16-30-B and CDJ2B16-50-B respectively.

\section{2) Solenoid valve}

In order to control the air cylinder, the two-position and five-port solenoid valve is adopted. Because there are four air cylinders, four solenoid valves whose models are all 4V210-08 are selected.

\section{3) Air pump}

Air pump is the most important energy device in the strapping machine. In our equipment, the OLF660AFD air pump is selected.

\subsection{Design of main circuit}

In the designed strapping machine, the frequency converter is used to control the three-phase squirrel cage induction motor machine. The start-stop control of the motor can also be realized through the change of the frequency. The main circuit of automatic strapping machine is shown in Fig. 6.

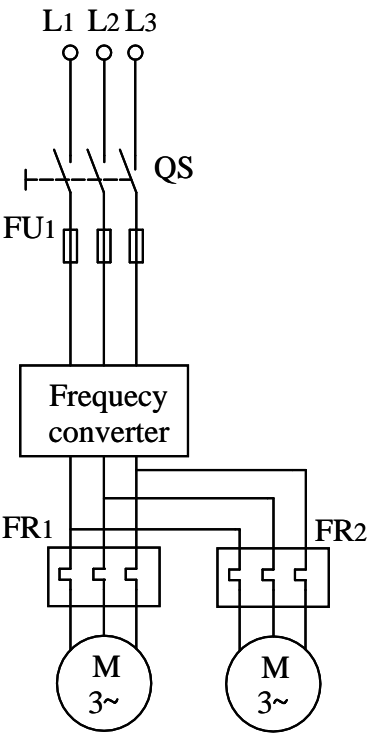

Fig.6 Main circuit of strapping machine

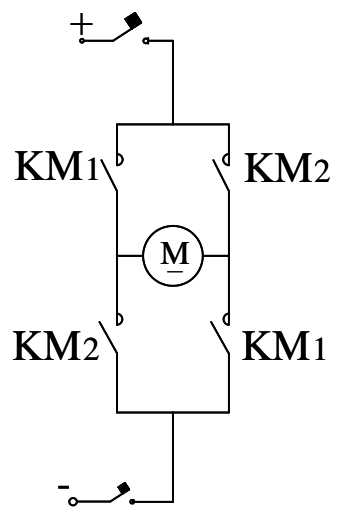

Fig.7 Forward/reversal rotation control circuit of DC motor 
In our designed machine, there are two DC motors need to be controlled. One is the 24V DC motor and the other is the 9V DC motor. The two motors are both separately excited DC motors. The forward/reversal rotation control circuit of the two motors is shown in Fig.7.

\subsection{I/O wiring diagram and allocation table of PLC}

In order to efficiently control the designed automatic strapping machine, the I/O resources need to be allocated firstly. The I/O wiring diagram is shown in Fig. 8. From the figure, we can see that there are two switches and one radio sensor attached to the input ports of PLC. The two switches (namely X0 and X2) complete the start and stop functions, respectively. The electric radio sensor is mainly used to determine whether a box has arrived at the designated location. The eight output ports of PLC are used to control four solenoid valves, two DC motors and two AC motors respectively.

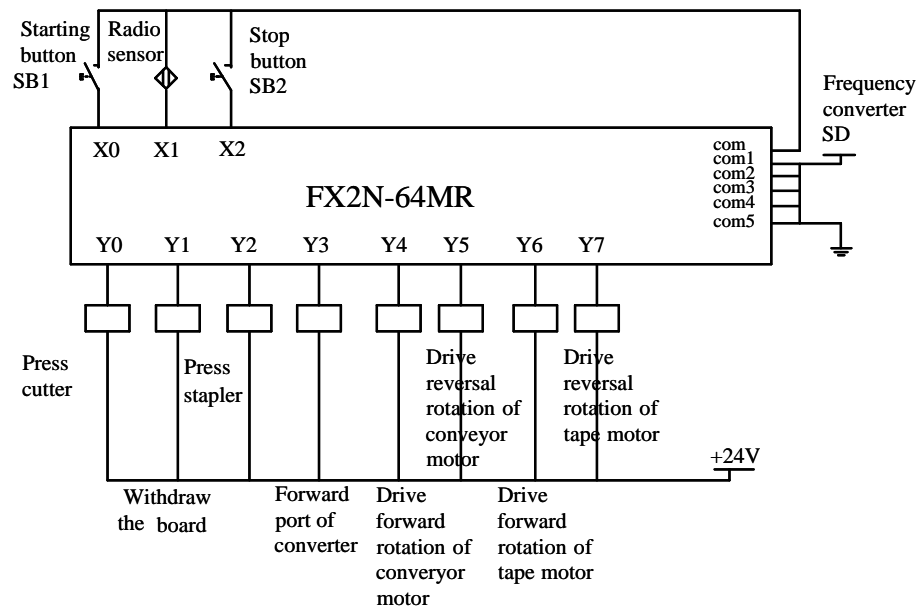

Fig.8 I/O wiring diagram

Table 1 gives the corresponding I/O allocation table of PLC. From the table, we can further see the functions of the input and output of the PLC.

Table 1 I/O allocation table of PLC

\begin{tabular}{|l|l|l|l|l|l|}
\hline \multicolumn{5}{|l|}{ Input } & Output \\
\hline $\begin{array}{l}\text { Input } \\
\text { equipments }\end{array}$ & Input ports & $\begin{array}{l}\text { Function } \\
\text { description }\end{array}$ & $\begin{array}{l}\text { Output } \\
\text { equipments }\end{array}$ & Out ports & Function description \\
\hline SB1 & X000 & Start button & KM1 coil & Y000 & Press cutter \\
\hline SQ1 & X001 & Detect box & KM2 coil & Y001 & Withdraw the board \\
\hline SB2 & X002 & Stop button & KM3 coil & Y002 & Press stapler \\
\hline & & & KM4 coil & Y003 & Start the conveyor belt \\
\hline & & & KM5 coil & Y004 & Send strapping tape \\
\hline & & & KM6 coil & Y005 & Tighten strapping tape \\
\hline & & & KM7 coil & Y006 & Seize the strapping tape \\
\hline & & & KM8 coil & Y007 & Release the strapping tape \\
\hline
\end{tabular}

\section{Experimental Test And Analysis}

In order to verify the effectiveness of the designed automatic strapping machine of express box for Tabobao sellers, an experiment is executed. Figs.9 (a)-(h) shows the experimental results.

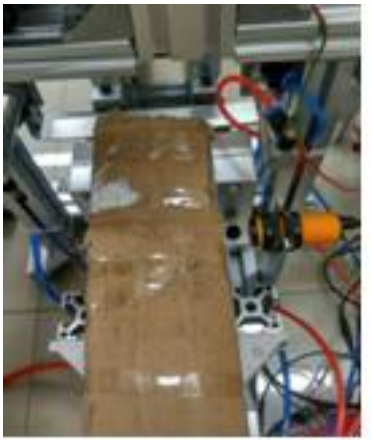

(a)

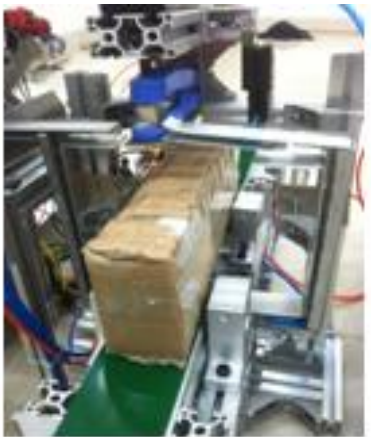

(b)

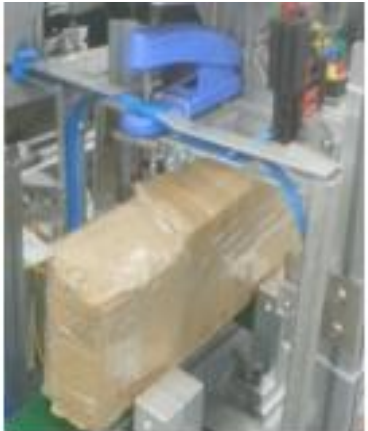

(c)

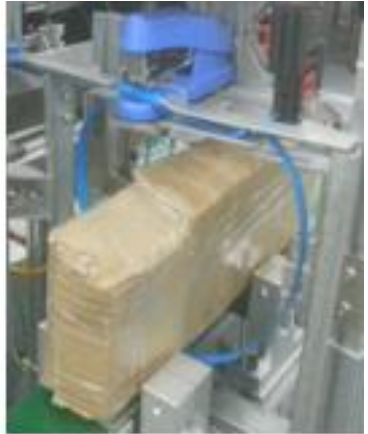

(d) 


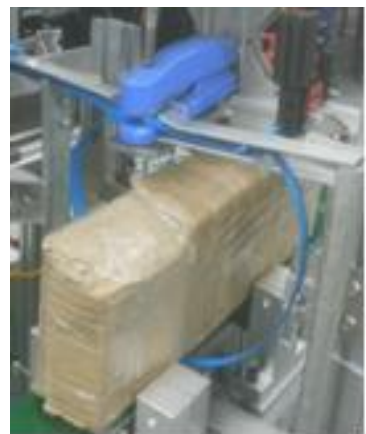

(e)

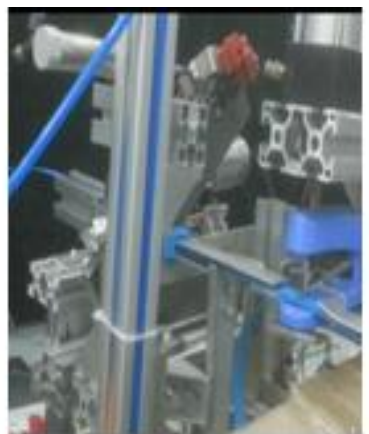

(f)

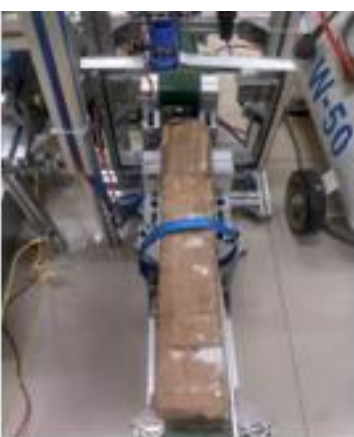

(g)

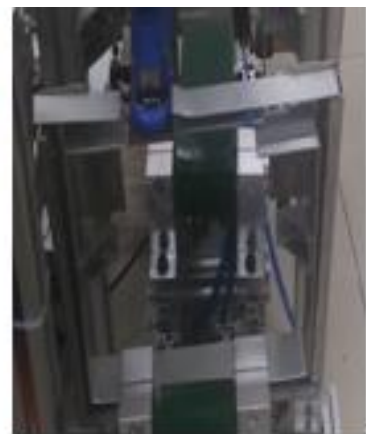

(h)

Fig.9 Experimental results

Fig.9 (a) show that the radio sensor has detected a box and then the conveyor belt will transport the box to the designated location as shown in Fig.9 (b). Then the board is withdrawn as shown in Fig.9(c). After that, the strapping tape is tightened as shown in Fig.9 (d). Fig.9 (e) shows that the stapler is pressed. Fig. 9(f) shows that the cutter is cutting the strapping tape. Fig. $9(\mathrm{~g})-(\mathrm{h})$ show that the tightened box is being moved out. From the experimental results in Fig.9, it can be seen that the designed machine can complete the strapping of an express box, which verifies the validity of the designed machine.

\section{Conclusion}

For the requirements of the Taobao sellers, a new automatic strapping machine is designed in this paper. The mechanical structure of the machine consists of board pushing equipment, connecting equipment of strapping tape, delivery and tightening equipment, and cutting equipment. The electronic components consist of programmable logic controller, AC motor, frequency converter and pneumatic components. In order to realize the control of the automatic strapping machine of express box, the main circuit of strapping machine, and the forward/reversal rotation control circuit of DC motor are also designed in this paper. Finally, an experiment is carried out, and the whole working process shows that the designed machine is valid and can meet the needs of Taobao sellers.

\section{References}

[1]. Y.G. Xie, X.W. Bai, G.C. Gao, Design of the wire binding machine about large bar, Metallurgical Equipment, 6, 2011, 21-24.

[2]. R.Z. Wei, S.J. Wang, Structural design of the vermicelli curling machine, Journal of Tianjin University of Technology, 29(2), 2013, 20-22.

[3]. S.J. Wang, R.Z. Wei, Structural design of the vermicelli strapping machine, Applied Mechanics \& Materials, 215, 2012, 217-220.

[4]. T.J. Cui, J.F. Liu, J.P. Li, X.J. Feng, Design of fruit tree seedings strapping machine, Journal of Agricultural Mechanization Research, 6,2014,101-104.

[5]. F.C. Wang, X.H. He, G.H. Liu, L. Wei, Design of sugarcane automatic binding machine based on UG software, 5, 2015,159-162. 